\title{
Analysis of Translation Mistakes of Compound Nouns from English into Arabic among Yemeni University EFL Students
}

\author{
Ebtissam Ezzy Alwan, Department of English, Dr. BAM University Aurangabad, India \\ Corresponding author: Ebtissam Ezzy Alwan [ebtissamizzy03@gmail.com]
}

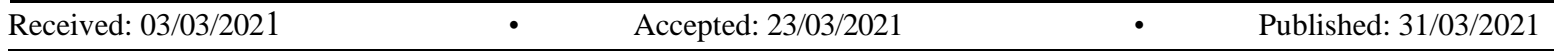

Abstract: The present study is devoted to the discussion on errors of English translation into Arabic with special reference to English compound nouns. The study is confined to the students of the Department of English, Faculty of education, Hodeidah University, Yemen as they face various difficulties and commit errors while translating English compound nouns into Arabic and vice versa. The researcher aims at examining multiple factors responsible for this state of affairs and make pedagogical suggestions to improve teaching and learning and thereby helping in the process of translation. For this study, the researcher has collected the data by conducting the test of 40 students of I to IV level, Department of English, Hodeidah University, Yemen. The test consists of one question having three items and each item has five words. In findings, the researcher concludes that the students face various difficulties and obstacles in the process of translating English compounds into Arabic. Moreover, they commit a number of mistakes while translating English compounds.
\end{abstract}

Keywords: English language translation; English as a foreign language; mother tongue or first language; second or foreign language; target language

\section{Introduction}

The English Language has been gaining importance by leaps and bounds and it has been acknowledged by a large number of academics in the world. It is regarded as the first language even in countries where it is not used as a first language. Some Scholars opine that almost all the persons in every nook and corner of the world more often than not use the English language (Al-Saggaf \& Rusli, 2020). While pointing out the importance of the English language, Warschauer et al. (2002) stated that in several countries, including Arab, English is used as the primary language in the class. It assists the students in learning their mother tongue.

In this connection, what Crystal (2012) has said is worth noting. He asserts that there is no doubt to state that learning English has been gradually increasing in almost all the countries, and Yemen is not an exception to this. Similarly, Nunan (2003) opines that Yemen's education has become significant due to English language courses in all academic institutions. As a result, the educational system in Yemen has been rapidly developing. Although the Arabic language is the native tongue in Yemen, nonetheless, after the 1990s, the Ministry of Education has made English compulsory from the age of six. Al Nagi and Hamdan (2009) have gone to the extent of describing Yemen as a bilingual country. They believe that learning the English language is likely to provide better opportunities to the students in their future life. This view has been upheld by many who argue that in almost all the fields of the 
country, the English language has been gaining ground. The examples of media, particularly social media, i.e., Facebook, education, technology, business, etc., well illustrate this.

The significance of the study lies in the fact that it is likely to go a long way to provide the guidelines to the students and enable them to use English compound nouns without committing errors during the process of translation. Besides, it is expected to help the students enhance their knowledge about the use of English compound nouns and thereby avoid errors while translating English compound nouns with the help of designing remedial tasks. For this purpose, the study suggests that the teachers should play a vital role in bringing to the notice of the students the errors which they commit in the process of translation.

No doubt translating English into Arabic has become a moot point over the years. The advocates of this plead about the advantages of it. They hold that this is quite obvious from the merits of proper translation into the mother tongue in the classroom. On the other hand, the opponents of this argument about the disadvantages and how it adversely affects quality. However, while emphasizing the use of the mother tongue, teachers have been cautioned about its overuse as it is likely to create the feeling in the minds of learners that they are not able to understand the foreign language so long as it is not translated into their native language. Of course, no one can disregard quality. Notwithstanding, as far as translation is concerned, the quality is a matter of relativity as almost all the translations have more or fewer drawbacks. This is obvious from the fact that all the studies on this issue have the same lists of translation ideas and concepts without having any fresh insight or adequate empirical evidence.

While translating English into Arabic, we must bear in mind that English consists of plenty of structural compound devices to communicate, whereas Arabic does not possess such devices. Apart from this, it is a herculean task to translate the languages which are culturally and structurally poles apart, and for this purpose, various techniques are used to obtain the equivalent words. Since translating English compound nouns is a complex pattern, it poses a big challenge for translators to translate.

Selkirk (1982) defined compound in English as a type of word structure made of two constituents, that each belongs to one of the categories of nouns, adjectives, verbs, or prepositions. In this way, in English, there are a large number of compound words or just compounds. On the other hand, the Arabic linguistic system consists of a few such words. In other words, a repository of such lexical compounds is limited in Arabic and consisting of $\mathrm{N}+\mathrm{N}$.

In addition to this, sometimes, the translators have no other alternative except to make some adjustments to obtain the same equivalent translation as the meaning of compound words is difficult to understand from its parts. On account of their semantic compactness, English compound constructions are not very often properly interpreted or translated. Arabic compounds are described as phrases with normal word-order, compressed into two or three lexical items. Arabic patterns of compounds are not productive in making new formations. Moreover, Arabic gives less importance to thought than the form. On the contrary, English gives more importance to the idea than the way it is formulated. To have a clear understanding, it is essential to know the difference in the structure between Arabic and English syntactic analysis of the compounds.

As far as Yemen is concerned, the teachers face various difficulties while teaching students if they only rely on the English language. Rababah (2003) finds fault with the large number of learners who rarely understand the English language. Hence, it is essential to use the mother tongue, particularly while teaching difficult portions of the language. He went to the extent of saying that for both teachers and learners teaching and learning English as a foreign language would not see the light of the day so long as the mother tongue is not used in the classroom. 
Being a lecturer in the Department of English, Faculty of Education, Hodeidah University, the researcher is well-aware of the situation in this university and to some extent in other universities in Yemen. The researcher has no hesitation to state that despite the importance of translation in practical life and obtaining command over the language, the English language programme either undervalues or turns a blind eye towards it. At the time of teaching English, a good deal of emphasis is given on structure and not on communication. While teaching translation subjects, English compounds are not paid much heed. Consequently, the students lack the knowledge of the English compound translation process and are unable to correctly translate English compounds. All these constitute the crux of the problem in translating English compounds into Arabic. Therefore, the researcher has focused her attention on the difficulties faced by the students while translating English compounds into Arabic.

Keeping all these in view, the researcher has made a humble attempt to dive deep into the factors which cause difficulties for both the teachers as well as the students while using the English language in different settings. Needless to say that English and Arabic are two separate languages and as such, they have different uses and rules. It is these differences that are mainly responsible for this state of affairs. Moreover, the confusion regarding the grammatical rules of both classic and colloquial Arabic has compounded these difficulties. The researcher has attempted to highlight the pros and cons of using the mother tongue and at the same time caution about the overuse of it.

What distinguishes this study from that of the earlier is that it has focused on examining the difficulties which Arab learners come across while dealing with compounds in the process of translation? The earlier studies have dealt with other aspects of difficulties while translating. The researcher believes that the students of English at the Faculty of Education, Hodeidah University face various difficulties while translating English compounds into Arabic. Hence, the researcher has undertaken the survey and conducted-test to find out the answer to the following questions:

a. What are the types of mistakes committed by Yemeni university EFL students while translating compound nouns from English into Arabic?

\section{Literature Review}

The present paper is devoted to the discussion on the arguments made by both those in favor of and against this issue. It is important to note that acquiring a new language has raised two contrasting views. The advocates of developing a new language argue that using translation into the mother tongue is likely to help in learning and dealing with a new language for teachers and students. On the other hand, the opponents of this view plead that using translation into the mother tongue is likely to create obstacles in the path of the students who intend to learn different languages.

To substantiate these arguments, some of the researches conducted on this issue have been cited. (Rababah, 2005) has pointed out that in the process of teaching; the foreign language plays a vital role. Having discussed the EFL learning situation in Yemen, he illustrates how teachers resort to mother tongue while explaining new words and literature of English. Although the CLT (Communicative Language Teaching) approach emphasizes teaching vocabulary items in context; however, vocabulary is still taught in isolation.

There is a difference of opinion about the use of the mother tongue. Some authors argue that it should not be used randomly and caution the teachers that its maximum use in the ELT classroom is likely to have an adverse impact. Whereas, others hold that teaching English bilingually and using L1 at an appropriate time is expected to make a positive contribution to English learning. Apart from this, some 
others assert that the limited use of the mother tongue would facilitate the learning of a foreign language and not obstruct it.

The research on bilingualism conducted by Hamers and Blanc (2000) clearly shows different cognitive functions in both languages. The essence of each language involves the linguistic system, morphology, semantics, phonology, syntax. Pragmatic as well as bilingualism requires a command over all these. At the same time, if needed, cognitively, we must be in a position to separate the languages. Besides, to make use of the information interchangeably, searching for the memory store is essential. For instance, Swain and Lapkin (2000) are of the opinion that as far as both linguistically and cognitively complex functions are concerned, disregarding the use of L1 amounts to setting aside the use of a vital cognitive tool.

It is quite apparent that no precise or clear criterion can be used for a common definition of the compound noun in English. Quirk (1973) defined compounding as the process of adding two bases together to constitute a new lexical item. While undertaking a review of literature it becomes quite clear that by and large, most of the writers hold the view that there is adequate scope for researching compounding. For example, Gagne (2002), Downing (1977), Bauer (1983), Spencer (1991), Sandra (1990), Warren (1978), Sag et al. (2002), Kim and Baldwin (2008), and Libben (1998) opined that there is a lot of debate on literature produced by research on compounding. The debate is focused on multiword expressions, complex word-formation, compound nouns, and the internal structure of compounds.

Amer (2020) pointed out that there are various nuances in meaning and scale of variations in the range of arguments as well as the empirical data. Nonetheless, there is a consensus on the view that a compound is a lexical unit having two or more elements. The purpose of combining two or more words is to transmit a clear meaning which cannot be done by a single separate word. By and large, compound words can be categorized as either hyphenated or written open (separate words), or written solid (closed).

Mustafa (2020) while referring to Onysko (2014), Benczes (2005), Vorobeva (2016), Yang and Li (2018), and Zibin, and Altakhaineh (2018) stated that in the past, there has been a lot of discussion on theoretical and empirical research papers on compound nouns regarding a cognitive semantic approach. Notwithstanding, it has been entirely focused on conceptual blending theory applying conceptual metaphor and metonymy theory. Hamawand (2011) in his book points out how to apply the theory of categorization on compound nouns of English in terms of prototype and periphery. Brinton and Brinton (2010), Katamba (2015) asserted that two free morphemes or lexical substructures, i.e., a head and a modifier constitute English compound nouns. What is important to note here is that as far as English compounds are concerned, the noun is always a head, however, the modifier may be a noun, adjective, or verb.

While making a distinction between English and Arabic, Sag et al. (2002) argued that English compounding is highly creative and innovative, more often than not it is used as a means of introducing new phrases or coining new words into the lexicon. On the other hand, Arabic is not very much resourceful. It does not have the same multiword expressions as an important part of the linguistic mechanism. What Amer (2004) said is also worth noting. He has stated that several compound nouns of English have been recognized either by original nouns which Arabic already has in its stock. For example, sun-in -law /sihr/, goat/tays/, or by one-word nouns (or adjectives/participles functioning as nouns). The present paper with the help of the empirical method aims at examining the errors committed by the students of Hodeidah University, Yemen while using English compound nouns. This area has hardly been covered by any researcher. Here lies the significance of this paper. 


\section{Materials and Methods}

\subsection{Research Design}

The present study has used a quantitative design. Creswell (2014) describes this design as the roadmap which guides the research to select the tools appropriate to attain the purpose of the study based on the questions of the research. It guides the researcher to focus on the topic under investigation with the help of the collection of data, instruments, and data analysis. There are various research designs and the present study has resorted to quantitative design. It assists the researcher to collect data from the responses of forty participants regarding the analysis of errors while using English compound nouns. Hence, it can be said that quantitative design is the most useful for obtaining the goals of the research. The findings of the study would not only apply to the students of Hodeidah University but also those of other universities in Yemen.

\subsection{Participants}

The research is based on descriptive, analytical, and empirical methods. That is to say, the researcher has undertaken a random survey of 40 students from level I to level IV, Dept. of English, Hodeidah University, Yemen. She has conducted a test and asked the students to give their responses on the issues of English compounds such as open compounds, closed compounds, and hyphenated compounds. It must be borne in mind that hyphenated compounds consist of two words joined by a hyphen and sometimes, more than two words. The students have been asked one question having three items. Each item consists of five words. The study pertains to the academic year 2020/2021. The researcher has used the statistical method to a random sample. In this way, the researcher has attempted to find out the errors of the students while using English compound nouns in the process of translating English into Arabic and the factors responsible for this state of affairs.

\subsection{Instrument}

Having reviewed the literature on this issue, the researcher has used this design. She has conducted the test keeping in view the level of the students in Hodeidah University, Yemen, and the objectives of the research. To ensure the validity of the results of the research, the opinions of three experts have been sought and their suggestions have been incorporated.

\section{Results}

The purpose of the study is to find out whether a large number of students commit mistakes while using English compound nouns in the process of translation. To substantiate the arguments, the researcher has tested 40 students of Dept. of English, Hodediah University, Yemen, to find out the mistakes they commit regarding English Compounds. The findings of the survey are as follows:

Table1. Description of the mistakes of English compound nouns while translating into Arabic

\begin{tabular}{|c|c|c|c|c|}
\hline \multirow{2}{*}{$\begin{array}{l}\text { English Compounds } \\
\text { Open Compounds }\end{array}$} & \multicolumn{2}{|c|}{$\begin{array}{l}\text { Number of Correct and } \\
\text { Incorrect Answers }\end{array}$} & \multicolumn{2}{|c|}{$\begin{array}{l}\text { Percentage of Correct and } \\
\text { Incorrect Answers } \\
\end{array}$} \\
\hline & $\begin{array}{c}\text { Correct } \\
\text { Answers }\end{array}$ & Incorrect Answer & $\begin{array}{l}\text { Correct } \\
\text { Answers }\end{array}$ & $\begin{array}{l}\text { Incorrect } \\
\text { Answers }\end{array}$ \\
\hline Ice cream & 19 & 21 & $47 \%$ & $53 \%$ \\
\hline High school & 0 & 40 & $0 \%$ & $100 \%$ \\
\hline Living room & 8 & 32 & $20 \%$ & $80 \%$ \\
\hline First aid & 3 & 37 & $7 \%$ & $93 \%$ \\
\hline
\end{tabular}




\begin{tabular}{lcccc}
\hline Web page & 10 & 30 & $25 \%$ & $75 \%$ \\
\hline Total & 40 & 160 & $20 \%$ & $80 \%$ \\
\hline Closed Compounds & & & & \\
\hline Snowball & 12 & 28 & $30 \%$ & $70 \%$ \\
Mailbox & 12 & 28 & $30 \%$ & $70 \%$ \\
Grandmother & 15 & 25 & $37 \%$ & $63 \%$ \\
Sometimes & 2 & 38 & $5 \%$ & $95 \%$ \\
Inside & 23 & 17 & $57 \%$ & $43 \%$ \\
\hline Total & 64 & 136 & $32 \%$ & $68 \%$ \\
\hline Hyphenated & & & & \\
Compounds & 6 & 34 & $15 \%$ & $85 \%$ \\
Long-term & 7 & 33 & $17 \%$ & $90 \%$ \\
Mother-in-law & 4 & 36 & $10 \%$ & $93 \%$ \\
Check-in & 3 & 37 & $7 \%$ & $25 \%$ \\
Up-to-date & 30 & 10 & $75 \%$ & $75 \%$ \\
IIl-treat & 50 & 150 & $25 \%$ & $74 \%$ \\
\hline Total & 154 & 446 & $26 \%$ & \\
\hline Total of All Answers & & & \\
\hline
\end{tabular}

The above table indicates that the students have faced many difficulties while translating English Compounds into Arabic. As far as the first question is concerned, it becomes obvious that the students face difficulties while translating English compounds into Arabic. In the table mentioned above, the number of students who have made an incorrect translation is (446), i.e., (74\%). This number is more than that of the students who have made a correct translation, i.e., (154), which comes to (26\%). Hence, it can be said without any doubt that the students have difficulties while translating English compounds into Arabic.

This might be due to that students are ill-equipped and lack the reading and writing skills, inadequate vocabulary and background knowledge of translation strategies, translating words without taking into consideration the sentences, doing literal translation, the meaning of some English words is difficult to comprehend even from its parts, i.e., "ill-treat" and "first aid"; non-availability of proper terms in Arabic dictionary, i.e., "long-term"; and ignorance of the functions of the English compounds. For the Yemeni students, English is a foreign language that has a number of compounds while Arabic has a limited number of compounds.

\section{Discussion}

Several studies so far have been undertaken on this issue have focused on the use of English compound nouns. The findings of the previous studies have pointed out the great significance of the use of English compound nouns and how it is beneficial for both students and teachers. (Rababah, 2005) has expressed his views on teaching foreign language in Yemen and pointed out how teachers use their mother tongue in the process of explaining new words of English. Besides, instead of teaching vocabulary items in context, they are taught in isolation. Most of the writers are of the opinion that a good deal of research can be undertaken on compounding nouns in English. The literature produced by research in this regard has given rise to a lot of discussions which has focused mainly on multiword expressions, complex words formation and compound nouns, and the internal structure of compounds 
The writings of Gagne (2002), Downing (1977), Bauer (1983), Spencer (1991), Sandra (1990), Warren (1978), et al. (2002), Kim and Baldwin (2008), and Libben (1998) can be cited to substantiate this argument. The study conducted by Hamawand (2011) has focused on the theory of categorization of English compound nouns in terms of prototype and periphery. Mustafa (2020) has devoted to the discussion on conceptual blending theory. Amer (2004) has pointed out that the number of English compound nouns have been recognized either by original nouns which are already found in Arabic stock. Amer (2020) asserted that a compound is a lexical unit having two or more elements and for conveying a clear meaning, combination of two or more words is essential. The findings of the present study have shown that number of scholars have been paying a great attention to the use of the mother tongue as it is regarded a tool to facilitate teaching English in the class and analyze the errors as well as mistakes committed by the students in the Universities in Yemen.

The analysis of errors and mistakes of English compound nouns is essential and indispensable for teaching and learning the English language. Without doing this, our cherished goal of teaching and learning correct and meaningful English compound nouns would remain a distant dream. However, we must bear in mind the factors which obstruct the process of translating English into Arabic. One of the main reasons for committing serious Interlingual errors is the difference in morphology in constructing compounds in the two languages. In addition to this, students' literal translation from Arabic to English and vice versa, failure of the teachers to translate correct patterns or concepts, etc. aggravates the situation. Consequently, the students fail to make out such concepts. While constructing English sentences, the factors like false application or ignorance of compound words and deducing false rules from what they observe as similar patterns and overgeneralization cannot be set aside. The arguments made in this paper are likely to go a long way in helping the teachers and students to teach and learn correct English compound nouns at the universities and schools in Yemen.

\section{Conclusion and Implications}

Based on the findings of the present study, certain recommendations have been made to help the teachers and students of English to improve the situation. To obtain mastery over compounds, it is indispensable that teachers should teach verbs, nouns, or adjectives which form compounds. They should pay sufficient attention to all three types of English compound nouns and teach the meaning and uses in the light of contextual situations. They should encourage the students to undertake heavy exercises and suggest recording any useful compound word which they notice. The teachers must examine the causes of errors committed by the students while using compounds. Every English compound word does not have an exact Arabic equivalent and vice versa. As such, literal translation into Arabic is likely to create more confusion leading to commit mistakes. The teachers are required to use the language log activity and adopt various methods and techniques while correcting errors. They need to design materials based on authentic resources such as newspaper clips, radio interviews, journal articles, TV programs, etc. They have to bring to the notice of the students the source of the errors, so the students to enable students to learn to differentiate between all forms of compound nouns.

To conclude, it can be said that a number of scholars have expressed their views on teaching English, and it has become a matter of great debate, particularly when it is taught as a target language in the class. On the one hand, some scholars hold the view that the use of English should be only confined to the class for improving the skills of the students. On the other hand, other scholars are of the opinion that Arabic should be used in the class for teaching the students and the best possible methods be adopted regarding English grammar, exercises, comprehension texts, speaking as well as writing skills. 
What is important to note here is that our primary focus should be on the student as he/she is the recipient. It is necessary to set a target for achieving our goal while teaching English in the class and find out the best ways to teach. The teacher is likely to grip in the dark if he teaches without making any preparation. To my mind, resorting to Arabic while teaching English in the class is likely to help the students to learn and comprehend the language in a better way. However, it should be borne in mind that depending thoroughly on the mother tongue is likely to defeat our purpose of teaching English. The best way would be to use both English and Arabic side by side. We cannot turn a blind eye towards our main goal of enabling the students to obtain maximum knowledge of English and make the best use of that for improving their language. To sum up, it can be said that in recent times using the mother tongue has drawn the attention of many scholars because it is regarded as a tool that facilitates teaching English in the class.

The present study aims at finding out the errors of English compound nouns committed by the students of Educational institutions in Yemen. It is based mainly on a random survey of the students, Dept. of English, College of Education, Hodeidah University, Yemen. It consists of forty students. The study pertains to the academic year 2020/2021. The study lays a great emphasis on the factors responsible for the various errors which students commit while translating English compound nouns into Arabic. It would be worthwhile to provide the facilities regarding the use of modern technologies to the students which would help them to learn English easily. However, from the findings of the present study, it can be concluded that students face various difficulties while translating English into Arabic. The universities are required to appoint teaching staff having mastery over both languages English as well as Arabic. They should be trained in translating English into Arabic. To attract competent teachers, the university has to pay high salaries to them.

The present study is confined to the English Department, Hodeidah University regarding the errors of English compound nouns committed by the students. It is a micro-level study. It would be better to undertake a macro-level study to find out the errors which students very often commit while using English compound nouns in the process of translating English into Arabic.

\section{References}

Al-Saggaf, M. A. \& Rusli, Z. A. N. (2020). Investigating the Types of Motivation of TESL Students in A Higher Education Institute in Malaysia. TESOL and Technology Studies, 1(1), 55-69.

Amer, W. (2004). Futurity in English and Arabic. Alqsa University Journal.

Amer, W. M., \& Menacere, K. (2020). The challenges of Translating English Compounds into ArabicFor Better or for Worse. Al Jinan, 11(1), 19-42.

Bauer, L. (1983). English word-formation. Cambridge: Cambridge University Press.

Benczes, R. (2005). Metaphor-and metonymy-based compounds in English: a cognitive linguistic approach. Acta Linguistica Hungarica, 52(2-3), 173-198.

Brinton, L. J., \& Brinton, D. (2010). The linguistic structure of modern English. John Benjamins Publishing.

Crystal, D. (2012). Spell it out: the singular story of English spelling. Profile Books.

Downing, P. (1977). On the creation and use of English compound nouns. Language, 810-842. 
Al Nagi, E., \& Hamdan, M. (2009). Computerization and e-Government implementation in Jordan: Challenges, obstacles and successes. Government Information Quarterly, 26(4), 577-583.

Gagné, C. L. (2002). Lexical and relational influences on the processing of novel compounds. Brain and Language, 81(1-3), 723-735.

Hamawand, Z. (2011). Morphology in English: Word formation in cognitive grammar. London: New York: Continuum.

Hamers, J. F., \& Blanc, M. (2000). Bilinguality and Bilingualism. Cambridge University Press.

Katamba, F. (2005). English words: Structure, history, usage. Psychology Press.

Kim, S. N., \& Baldwin, T. (2008). Benchmarking noun compound interpretation. In Proceedings of the Third International Joint Conference on Natural Language Processing: Volume-I.

Libben, G. (1998). Semantic transparency in the processing of compounds: Consequences for representation, processing, and impairment. Brain and language, 61(1), 30-44.

Mustafa, S. K. (2020). CATEGORIZATION OF COMPOUND NOUNS IN KURDISH AND ENGLISH. LLT Journal: A Journal on Language and Language Teaching, 23(1), 104-115.

Nunan, D. (2003). The impact of English as a global language on educational policies and practices in the Asia-Pacific Region. TESOL quarterly, 37(4), 589-613.

Onysko, A. (2014). Figurative processes in meaning interpretation: A case study of novel English compounds. Yearbook of the German Cognitive Linguistics Association, 2(1), 69.

Quirk, R. (1973). A University Grammar of English. London: Longman.

Rababah, G. (2005). Communication problems facing Arab learners of English. Journal of Language and Learning, 3(1), 180-197.

Sag, I. A., Baldwin, T., Bond, F., Copestake, A., \& Flickinger, D. (2002, February). Multiword expressions: A pain in the neck for NLP. In International conference on intelligent text processing and computational linguistics (pp. 1-15). Springer, Berlin, Heidelberg.

Sandra, D. (1990). On the representation and processing of compound words: Automatic access to constituent morphemes does not occur. The Quarterly Journal of Experimental Psychology, 42A, $529-567$.

Selkirk, E. O. (1982). The syntax of words. Linguistic Inquiry Monographs Cambridge, Mass, (7).

Spencer, A. (1991). Morophological theory. Cambridge: MA: Blackwell Publisher.

Swain, M., \& Lapkin, S. (2000). Task-Based Second Language Learning: The Uses of the First Language. Language Teaching Research, 4(3), 251-274.

Vorobeva, Y. (2016). Cognitive-pragmatic approach to the meaning of new compound nouns in English. International Journal of Humanities and Social Science, 6(4), 117-124. 
Warren, B. (1978). Semantic patterns of noun- noun compounds. Goteborg: Acta University Gothoburgensis.

Warschauer, M., Said, G. R. E., \& Zohry, A. G. (2002). Language choice online: Globalization and identity in Egypt. Journal of Computer-Mediated Communication, 7(4), JCMC744.

Yang, R., \& Li, D. (2018, July). Differences between Translation of Chinese Compound Nouns into English Compound Constructions 'Deverbal Noun-Noun'and 'V.-ing-Noun'. In 3rd International Conference on Contemporary Education, Social Sciences and Humanities (ICCESSH 2018) (pp. 806-811). Atlantis Press.

Zibin, A., \& Altakhaineh, A. R. M. S. (2018). An analysis of Arabic metaphorical and/or metonymical compounds: A cognitive linguistic approach. Metaphor and the Social World, 8(1), 100-133. 